\title{
Eyelid Nevus
}

National Cancer Institute

\section{Source}

National Cancer Institute. Eyelid Nevus. NCI Thesaurus. Code C3880.

A nevus occurring in the eyelid. 